\title{
The Guideline on Procedures with Respect to Vulnerable Persons Appearing Before the Immigration and Refugee Board of Canada: A Critical Overview
}

\author{
Janet Cleveland
}

\begin{abstract}
This paper presents a critical overview of the Guideline on Vulnerable Persons, adopted by Canada's Immigration and Refugee Board (IRB) in December 2006 with the goal of providing procedural accommodations for vulnerable individuals appearing before the Board so that they are not disadvantaged in presenting their cases. Although the Guideline is a step in the right direction, it has several serious shortcomings, notably the fact that it is purely procedural in scope, applies only to persons whose ability to present their case is severely impaired, and does not give sufficient weight to expert opinions by mental health professionals.
\end{abstract}

\section{Résumé}

Cet article propose un coup d'eil critique sur le document Directives sur les procédures concernant les personnes vulnérables qui comparaissent devant la CISR, adopté par la Commission de l'immigration et du statut de réfugié $d u$ Canada en décembre 2006 dans le but de fournir des accommodements en matière de procédure pour les personnes vulnérables appelées devant la Commission, et cela afin quelles ne soient pas désavantagées pour présenter leurs cas. Bien que la Directive soit un pas dans la bonne direction, elle a plusieurs manquements sérieux, notamment le fait que sa portée est limitée en matière de procédures seulement, qu'elle ne s'applique uniquement qu'aux personnes qui ont des handicaps graves pour présenter leur cas, et n'accorde pas suffisamment d'importance à l'opinion d'expert présentée par les professionnels en matière de santé mentale.

\section{Introduction}

For many years, refugee advocates and mental health professionals have demanded that Canadian immigration authorities adopt policies to meet the needs of psychologically vulnerable asylum seekers and permanent residents. On December 15, 2006, Canada's Immigration and Refugee Board (IRB or Board) issued a guideline designed to respond to some of these concerns, Guideline on Procedures with Respect to Vulnerable Persons Appearing Before the IRB (Guideline on Vulnerable Persons, or Guideline 8). ${ }^{1}$

Psychological vulnerability may detrimentally affect asylum seekers and permanent residents in a variety of ways. First, it may affect the person's ability to coherently and persuasively present her case before the IRB. Procedural changes (e.g., allowing a support person to be present) will often be helpful but may not be sufficient to overcome this disadvantage. For example, a person who has experienced torture or rape may well have difficulty telling her story to the Board despite procedural adjustments. Her account may still be marred by inconsistencies, vagueness, omissions, late disclosure, apparent lack of emotion, or other characteristics that can easily be mistaken for signs of untruthfulness. To ensure that vulnerable persons are not disadvantaged in presenting their case, it is therefore essential to take psychological problems into account when assessing the person's credibility in addition to allowing procedural accommodations.

Second, psychological problems may affect the person's ability to seek state protection or to relocate, and should therefore be considered when analyzing these aspects of the refugee claim. Third, some permanent residents or refugees may face removal for mental health related criminal offenses such as an assault committed while in the grip of psychot- 
ic delusions or a robbery linked to drug addiction. In such cases, it would seem reasonable to take diminished responsibility into account. Fourth, psychological vulnerability should be considered in deciding whether a detained asylum seeker should be transferred to a community facility or released under a bond. ${ }^{2}$ In the United Kingdom, for example, it is now unlawful to detain asylum seekers who have been tortured. ${ }^{3}$

Finally, the heightened vulnerability of psychologically disturbed persons is a relevant factor when assessing the risks they would face if returned to their country of origin. For example, a Roma woman who had suffered for years from severe depression, anxiety, and agoraphobia following an attack by skinheads was found to have compelling reasons not to return to Hungary, although the risks that she would face there would not amount to persecution for a less psychologically fragile person. ${ }^{4}$ Similarly, the claim of an Ethiopian asylum seeker with chronic bipolar disorder and a history of suicide attempts was accepted on the grounds that the severe stigmatization and discrimination that she would experience in Ethiopia because of her mental illness amounted to persecution. ${ }^{5}$

These are just some examples of the many problems faced by vulnerable persons seeking status in Canada. The Guideline on Procedures with Respect to Vulnerable Persons Appearing Before the IRB (Guideline 8) addresses only one of these issues, that of procedural adjustments designed to attenuate some of the difficulties faced by vulnerable persons during IRB procedures. Although a praiseworthy initiative, the Guideline therefore falls far short of responding to all the needs of vulnerable persons appearing before the IRB.

In this paper, I first present a critical summary of Guideline 8 , followed by an analysis of IRB and Federal Court decisions involving the Guideline. In a third section, I briefly critique the assumption expressed in Guideline 8 that serious vulnerability is exceptional among asylum seekers. Finally, I refute a number of misconceptions concerning reports by mental health professionals contained in the IRB Training Manual on Victims of Torture. ${ }^{6}$

\section{Critical Overview of Guideline 8}

\section{Definition of Vulnerable Persons}

Vulnerable persons are defined as "individuals whose ability to present their cases before the IRB is severely impaired,"7 but also as individuals who have "severe difficulty in going through the hearing process or other IRB processes without special consideration being given to their individual situations,"8 which appears to be a somewhat broader standard. The main goal of procedural accommodations is to ensure that "the person is not disadvantaged in the presentation of their case," ${ }^{\prime}$ which indicates that the focus is more on en- suring fairness than on minimizing distress. However, another objective is to "prevent vulnerable persons from being traumatized or re-traumatized by the hearing process or other IRB process." 10 This suggests that the Board should be prepared to adjust its procedures if the regular process is likely to cause significant distress, even if the person may be reasonably able to testify.

This more liberal interpretation is consistent with the remedial aim of Guideline 8. For example, a refugee claimant who is very reluctant to recount her rape may be able to overcome her reluctance and tell her story, but at the cost of reviving suicidal urges. In this instance, the person is ultimately able to present her case, but at a tremendous cost to her psychological integrity. An overly narrow interpretation of the Guideline focusing exclusively on impairment of the person's ability to present her case could lead to a refusal to recognize such a person as vulnerable and a failure to provide procedural accommodations that were in fact needed.

Vulnerability may be due to a variety of factors, ${ }^{11}$ including (but not limited to):

- experiential factors, notably having experienced or witnessed torture, genocide, rape, gender-related persecution or other severe mistreatment; and

- innate or acquired personal characteristics such as age, mental or physical illness, or mental or physical handicap.

The Guideline states repeatedly that many of the individuals appearing before the IRB experience some degree of vulnerability and have difficulty going through the process for reasons such as language and cultural barriers, previous traumatic experiences, or the profound impact that the IRB decision may have on the person's life. ${ }^{12}$ Having recognized these facts, the IRB could logically have concluded that a large proportion of those appearing before it may need some form of procedural accommodation. Instead, the Guideline emphasizes that it applies only to "the more severe cases of vulnerability" involving "difficulties which go beyond those that are common to most persons appearing before the IRB," ${ }^{3}$ while asserting that the IRB should treat everyone appearing before it with sensitivity and respect. ${ }^{14}$

If a significant proportion of individuals appearing before the IRB are, in fact, vulnerable, why not recognize them as such? Most of the procedural accommodations envisaged in Guideline 8 are not particularly taxing for the system. Why restrict them to cases in which the person's ability to present their case is severely impaired? Surely procedural accommodations should be allowed whenever there is reason to believe that they might make it easier for the person to tell their story or simply decrease the person's level of distress. Instead of setting such a high threshold for recognition as a vulnerable person it would seem to make more sense to set a lower 
initial threshold, but then to take into account the relative severity of the person's impairment when deciding whether measures with broader systemic implications, such as priority scheduling, are warranted.

\section{Identification of Vulnerable Persons}

A person may be identified as vulnerable at any stage of the proceedings, preferably at the earliest opportunity. ${ }^{15}$ The member assigned to hear the case on the merits is not bound by an identification made prior to the hearing. ${ }^{16}$ Thus, the assigned member can recognize a person's vulnerability and order procedural adjustments even if this was refused before the hearing, but can also reverse a pre-hearing decision identifying the person as vulnerable. This latter perspective is liable to generate anxiety for the vulnerable person, which would seem to defeat the purpose of pre-hearing identification. It is to be hoped that assigned members will refrain from modifying pre-hearing decisions unless new evidence has been submitted.

\section{Designated Representative}

A designated representative will only be appointed if the person is either under eighteen years of age or unable to appreciate the nature of the proceedings, ${ }^{17}$ a standard which is considerably narrower than the criteria for recognition as a vulnerable person. ${ }^{18}$ In a number of cases, the Board has refused to appoint a designated representative but has gone on to recognize that the person was vulnerable and allowed procedural accommodations. ${ }^{19}$ On the other hand, if an adult's ability to understand the proceedings is so impaired as to warrant the appointment of a designated representative, she is necessarily also severely impaired in her ability to present her case and should automatically be considered vulnerable.

\section{Nature of Procedural Accommodations}

The Board has "a broad discretion to tailor procedures to meet the particular needs of a vulnerable person" 20 such as allowing the person's lawyer to proceed first, allowing the presence of a support person, creating a more informal setting, or "any other procedural accommodation that may be reasonable in the circumstances". 21 Proceedings involving vulnerable persons should generally be scheduled on a priority basis given that the anxiety generated by delays may be particularly detrimental for such persons. ${ }^{22}$ When questioning a vulnerable person, the Board must "attempt to avoid traumatizing or re-traumatizing" the person. ${ }^{23}$ More specifically, Board members and Refugee Protection Officers are encouraged to adopt the approach outlined in the IRB's Training Manual on Victims of Torture in all cases involving vulnerable persons. ${ }^{24}$ The Training Manual will be discussed in greater detail below.

\section{Establishing Vulnerability: Expert Reports and Other} Forms of Evidence

Although an expert report or other independent credible evidence is the preferred way to prove vulnerability, ${ }^{25}$ this is not obligatory. ${ }^{26}$ In several cases, the IRB has concluded that a person was vulnerable based on a letter from counsel describing behaviour consistent with mental health problems. There have also been cases in which the Board recognized the person as vulnerable and ordered an early hearing on its own initiative based simply on the claimant's Personal Information Form (PIF) as well as behaviour observed by Board staff. ${ }^{27}$ The absence of expert evidence will not necessarily lead to a negative inference concerning vulnerability; the Board must consider whether it was "reasonably possible" to obtain such evidence. ${ }^{28}$ It remains to be seen whether the often prohibitive cost of an expert assessment will be taken into account when deciding whether it was reasonably possible to submit such evidence.

The decision as to whether a person is vulnerable and needs procedural accommodations will almost always be made before the hearing on the merits begins, and therefore before the Board has had the opportunity to assess the person's credibility. ${ }^{29}$ The Guideline clearly envisages that the decision as to vulnerability will generally be made on the basis of allegations whose credibility has not been tested. ${ }^{30}$ Indeed, it specifies that identifying a person as vulnerable does not imply that the underlying facts are true or that the case is well-founded. ${ }^{31}$

On the other hand, the Guideline also states, "The weight given to the [expert's] report will depend, among other things, on the credibility of the underlying facts in support of the allegation of vulnerability. ${ }^{32}$ This rule is relevant when the Board is deciding the merits of the case after hearing the claimant's testimony, although often applied too restrictively. However, it will rarely be relevant to a Guideline 8 application. At this stage of the proceedings the Board is not dealing with issues that lie within its exclusive jurisdiction, namely assessment of the person's credibility and of the merits of their claim, but rather with an issue that is primarily within the field of expertise of mental health professionals, namely psychological impairment. In almost all cases involving Guideline 8 applications, the Board has not had the opportunity to hear the applicant and assess her credibility, so it is hard to see on what basis the Board can override the conclusions of a mental health professional who has interviewed or treated the person and reached the professional opinion that she is psychologically fragile.

In short, if a qualified mental health professional submits a reasonably detailed report based on an assessment conducted according to professional standards and concludes that the person has mental health problems likely to impair her abil- 
ity to present her case, this should be treated as conclusive proof of vulnerability for the purpose of procedural accommodations. On the other hand, the decision as to which procedural accommodations are appropriate remains within the Board's discretion insofar as it involves balancing the needs of the vulnerable claimant and the limitations inherent to Board resources and procedures, although significant weight should be given to the mental health professional's suggestions in this regard.

The fact that a person is initially identified as vulnerable does not prevent the Board member assigned to the case from rejecting the person's claim on the merits. ${ }^{33}$ Conversely, the decision regarding vulnerability should be kept separate from the merits of the case. A person may be genuinely in need of procedural accommodations even if there are indications that her case is not well-founded. The right to procedural accommodations is based on the right to a fair hearing irrespective of the merits of the case. Even if there are serious inconsistencies or defects in pre-hearing procedures, this should not be taken into account when deciding an application for procedural accommodations, precisely because such inconsistencies or defects may well be linked to the person's impairment. For example, if an asylum seeker fails to disclose sexual abuse until shortly before the hearing or makes contradictory statements, this should not be held against her when deciding whether she is vulnerable.

\section{Decisions Involving Guideline 8}

The IRB does not formally track decisions involving Guideline 8 , so no precise figures are available. However, an informal tracking mechanism initiated in mid-2007 shows that there have been very few applications under the Guideline since its adoption. Refugee Protection Division (RPD) records indicate that, as of May 2008, there had been approximately twenty-four decisions in Montreal concerning applications to have a person declared vulnerable, twenty-one in Toronto, and thirteen in Vancouver. ${ }^{34}$ This is a tiny number, especially compared to the number of decisions rendered by the RPD each year. Although no figures were available for the other two IRB divisions, the situation there appears to be similar. Note that it is impossible to track cases in which Guideline 8 may have been cited orally during a hearing in support of a request for some form of procedural adjustment if this was not mentioned in the final decision.

The dearth of applications under Guideline 8 is all the more surprising given that very few have been refused. According to the internal RPD figures mentioned above, two out of twenty-four applications were refused in Montreal, two out of twenty-one in Toronto, and three out of thirteen in Vancouver, for an overall refusal rate of about 8 per cent. Furthermore, in several cases in which the Board refused to identify the person as vulnerable, it nonetheless made certain procedural accommodations. These figures suggest that there is a willingness on the part of the Board to make procedural accommodations where warranted, and that counsel should perhaps consider making greater use of Guideline 8 when there is reason to believe that the client is likely to have serious difficulty dealing with IRB proceedings.

For the period between December 2006 and July 2008, I found ${ }^{35}$ eleven cases citing Guideline $8,{ }^{36}$ including an RPD decision and two Federal Court decisions which I will discuss in greater detail because they illustrate some of the Guideline's potential limitations.

\section{Refugee Protection Division Decision}

In a domestic violence case involving a fifty-seven-year-old Zimbabwean woman, the Board refused to recognize the applicant's vulnerability despite a detailed report in which the psychologist posed a diagnosis of post-traumatic stress disorder (PTSD) with significant depressive symptoms, affirming that the claimant had "experienced flashback and aversive emotional arousal during the interview" and that she had concentration and memory problems which would probably be exacerbated during the hearing. ${ }^{37}$ The Coordinating Member wrote:

I am not satisfied that the claimant's ability to present her case has been severely impaired within the meaning of subsection 2.1. The Guideline is not intended to apply to every case in which there has been serious trauma nor does it automatically apply in every case where PTSD (or other relevant disorder) has been diagnosed. There is no evidence in the present case of difficulties that are particularly severe or that cannot be handled in the usual manner. It simply does not meet the threshold under the Guideline. ${ }^{38}$

The member nonetheless accepted most of the procedural accommodations requested (female panel, informal hearing), but based his decision on the Guideline on GenderBased Persecution rather than the Guideline on Vulnerable Persons.

This decision clearly illustrates the problems posed by the provisions limiting application of the Guideline to the "more severe cases of vulnerability" 39 in which the person's ability to present their case is "severely impaired." 40 In practice, the Board recognized that the claimant was in need of procedural accommodations, but refused to identify her as vulnerable under Guideline 8 for the sole reason that she was no more vulnerable than many other claimants. In my view, this result is completely contrary to the objectives of the Guideline. However, the fundamental problem lies not with the Board member's interpretation of the threshold criteria, although I 
find it unduly restrictive, but rather with the criteria themselves.

As discussed above, restricting application of Guideline 8 to the very severely impaired is unfair. If there is credible evidence that the person is likely to have difficulty presenting her case before the Board, how can the fact that many other claimants experience similar difficulties justify a refusal to grant procedural accommodations that could help the person to more effectively present her case or simply reduce her distress? The decision to identify a person as vulnerable and to grant appropriate procedural accommodations should be based on the individual's limitations and needs, not on ranking the person on a scale of relative severity of impairment compared to other claimants. In other words, the fact that a large number of claimants may suffer from PTSD, depression, anxiety, or other forms of vulnerability cannot rationally justify refusal of procedural accommodations to those who actually need them simply because their level of impairment is unexceptional.

This decision also illustrates the potential for error inherent in allowing a Board member to override a mental health professional's report on an issue at the heart of the latter's expertise, psychological impairment, especially without having heard the claimant. The above-cited case of the Zimbabwean woman illustrates this point. The Board concluded that there was no reason to believe that her problems were particularly severe. To a mental health professional, however, her symptoms sound quite serious, particularly the fact that she displayed "flashback and aversive emotional arousal" 41 during the assessment interview. In clear, this indicates that as she was sitting in the psychologist's office recounting her traumatic experiences, she suddenly switched from remembering to actually reliving the experience, somewhat like a waking nightmare. During this flashback the woman showed signs of intense distress which probably included physiological reactions such as shaking, gasping, or sobbing. The psychologist also observed concentration and memory problems. This clinical picture strongly suggests that the woman would be likely to display similar symptoms during her refugee claim hearing, and that she was therefore a vulnerable person in need of procedural accommodations. Although the Board member in this instance was visibly competent and caring, he appears to have misjudged the severity of the claimant's impairment, probably in part because he did not fully understand the specialized terminology used by the psychologist.

\section{Federal Court Decisions}

At the time of writing, there have been only two Federal Court cases involving Guideline 8. In Orozco, ${ }^{42}$ the Federal Court dismissed an application for judicial review of a deci- sion refusing to reopen a refugee protection claim based on sexual orientation. The Court adopted a restrictive interpretation of Guideline 8, asserting that "a duty to accommodate above and beyond those already built into the IRB processes is triggered only in cases of severe vulnerability where an applicant's ability to present their cases [sic] is significantly and considerably impaired." 43 The Court also interpreted the Guideline's provisions concerning the content of expert reports as if they established minimal standards, whereas they are more likely intended as a "best practices" model aimed at helping clinicians understand what information should ideally be included in a full-fledged expert report.

Although both the RPD and the Federal Court discussed Guideline 8 at some length, it was arguably irrelevant to the proceedings. The initial claim was decided in 2005 , before the adoption of Guideline 8. There was no allegation of vulnerability, no psychologist's report, and no request for procedural accommodations at the initial refugee protection hearing. Nor did subsequent counsel identify any accommodations that should have been made. The issue of vulnerability was first raised at the application to reopen, based on a psychologist's assessment conducted 15 months after the refugee hearing. The issue before both the RPD and the Federal Court was not whether the applicant was a vulnerable person as defined in Guideline 8, nor whether procedural accommodations should have been made, but instead, whether a breach of natural justice had occurred at the initial hearing.

In Sharma ${ }^{44}$ the Federal Court rejected an application for judicial review of a decision refusing refugee status to an Indian man who claimed to have been tortured by the police after a bomb went off in front of his office. His only son was also arrested and died of a brain hemorrhage while in police custody. The son's body carried multiple marks of torture.

The IRB (correctly, in my view) refused a pre-hearing application to designate a representative for the claimant and his wife but identified them as vulnerable and allowed them to be accompanied by a support person at the hearing, based on reports by the claimants' psychotherapist, social worker, and physician indicating that Mr. Sharma suffered from PTSD and depression. The medical report, citing $\mathrm{X}$-ray results, also indicated that Mr. Sharma suffered from ongoing pain and limping due to a hip stress fracture, allegedly caused by having been suspended from the ceiling by his feet for extended periods during police interrogation. This was consistent with Indian hospital records documenting the treatment received immediately after the alleged torture. His wife was diagnosed with anxiety and major cardiac problems.

The Federal Court decision is troubling for two main reasons. First, the Federal Court asserts that it is entirely up to the Board member to decide whether the claimants' psychological vulnerability affected their ability to testify, without 
even discussing the Board's decision to totally discount all four medical and psychological reports submitted by the claimants. In particular, the Court said nothing about the Board's complete failure to discuss the Canadian medical report linking the claimant's physical injuries to the alleged torture as well as confirming his psychological problems. This is contrary to the well-established principle that the Board must consider the psychological or medical evidence before it, ${ }^{45}$ particularly a report based in part on objective evidence such as an X-ray. ${ }^{46}$ Second, the Court concluded that "the Board member" was sensitive to the claimants' vulnerability and made the necessary procedural accommodations, ignoring the fact that two separate members were involved. Procedural accommodations were made by the Coordinating Member, who indeed seemed sensitive to the claimants' vulnerability, whereas the presiding member was openly confrontational and not in the least sensitive. The Court seems to imply that once procedural accommodations have been made, refugee claimants cannot subsequently argue that their psychological vulnerability prevented them from adequately presenting their case. This is incompatible with the remedial purpose of Guideline 8 and more particularly with s. 10.1, which states:

The IRB ensures that all those who appear at its hearings or other proceedings are questioned with sensitivity and respect. This obligation is all the more important in the case of vulnerable persons. In probing the information provided by the person, the IRB will attempt to avoid traumatizing or re-traumatizing the vulnerable person. ${ }^{47}$

The fact that procedural accommodations have been made in no way decreases the Board's obligation to show a particularly high level of sensitivity and respect to vulnerable persons and to do everything in its power to avoid traumatizing them. This is incumbent on the Board in all cases in which a person has been recognized as vulnerable, without any need for counsel to explicitly remind the Board of its obligations.

In the Sharma case, the transcript of the IRB hearing shows that the Refugee Protection Officer and the presiding Board member, Sajjad Randhawa, took turns aggressively questioning the claimants, focusing on minute details and minor inconsistencies. Despite the chaotic and hostile manner in which he was questioned, the principal claimant's testimony was dignified and coherent. Indeed, the claimants told the same story throughout the proceedings, from the initial port-of-entry interview through detention proceedings to the refugee status hearing. The medical and psychological evidence was consistent with the claimant's description of the torture he underwent. After reading the entire Federal Court file, I believe that the Board hearing was profoundly unfair and that the Board decision flies in the face of the evidence. It would be of little theoretical interest to discuss the Board's decision in any detail because it focused on the particular facts of the case. Furthermore, the Board simply ignored that the claimants had been identified as vulnerable without discussing the issue.

It is perhaps paradoxical that, despite the hostile questioning and his well-documented psychological problems, Mr. Sharma's testimony was frank, plausible, and consistent. The problem did not lie with his inability to present his case, but rather with the Board member's failure to fairly and competently examine the evidence.

\section{Is Serious Vulnerability Exceptional?}

Guideline 8 is premised on the assumption that only a small proportion of the individuals appearing before the Board are vulnerable enough to require procedural accommodations. However, the scientific literature on psychological difficulties among adult asylum seekers suggests that this premise is erroneous (and this, without even taking into account vulnerabilities not due to mental health problems): first, because the prevalence of mental health difficulties tends to be quite high among asylum seekers during the first few years following their arrival, which is generally the period during which they will be involved in proceedings before the Board; and second, because many of these mental health problems are likely to impair the person's ability to adequately present their case before the Board. This question is too complex to examine in any depth in this paper, so I will just mention a few quick facts about the prevalence and impact of posttraumatic stress disorder and depression, the mental disorders that most commonly affect asylum seekers.

Asylum seekers are highly likely to suffer from PTSD and depression because they typically have been exposed to multiple traumatic events involving interpersonal violence, have suffered multiple losses, and are subject to considerable stress and insecurity linked to exile and the refugee claims process itself. The likelihood of developing PTSD is generally much higher in response to interpersonal violence, especially sexual violence, than following non-intentional trauma. ${ }^{48}$ In addition, the probability of suffering from PTSD usually increases with the number of traumatic events to which the person is exposed. ${ }^{49}$ In Mexico, for example, a study found that rates of PTSD were double the single-trauma rate among adults who had experienced two to three traumas, and triple the single-trauma rate among adults with four or more traumas. ${ }^{50}$ Repeated traumatization not only increases the risk of developing PTSD but also reduces the likelihood of recovery, and is often associated with particularly severe and chronic mental health problems. 
PTSD prevalence tends to be high in conflict zones. For example, a 1998 study of a large representative sample of the population of Algiers who had been exposed to widespread massacres for several years found that 37 per cent of the population had experienced full PTSD symptoms. ${ }^{51}$ In countries that have gone through prolonged and extreme conflict, rates of PTSD may remain high for many years postconflict. Thus, the same study found a PTSD prevalence of 28 per cent in a representative sample of the Cambodian population, some twenty years after the Khmer Rouge genocide and about eight years after low-intensity warfare had ended. ${ }^{52}$ This is far higher than the 8 per cent lifetime prevalence in the United States. ${ }^{53}$

Individuals with PTSD are highly likely to also experience other mental disorders, particularly depression. ${ }^{54}$ In Australia, for example, almost 60 per cent of individuals who had suffered from PTSD in the previous year had also experienced major depression during that period. ${ }^{55}$ High rates of concurrent PTSD and depression are common among resettled refugees and asylum seekers. ${ }^{56}$ Functional impairment is typically far greater among persons diagnosed with both PTSD and depression than those diagnosed with PTSD alone. $^{57}$

Recurrent, involuntary, and distressing re-experiencing of the traumatic events is the hallmark of PTSD. Typically, the person is periodically flooded with vivid images (and sometimes sounds, smells and other bodily sensations) of the traumatic events, both during waking hours and in nightmares. Intrusive recollections are often triggered by reminders of the traumatic events, which may include seemingly innocuous cues (for example, seeing a red truck after a serious accident involving a similar vehicle). ${ }^{58}$ Although traumatic memories are vivid, they are often narrowly focused on the core features of the event while peripheral features are not encoded. ${ }^{59}$ For example, hold-up victims may be so intensely focused on the aggressor's gun that they do not register details of the person's face or clothing. Perception of time is often distorted in relation to traumatic events. ${ }^{60}$ In some cases, confusion or inability to remember details about traumatic events may occur because the person is overwhelmed by intense emotions that paralyze her ability to think clearly (somewhat akin to "blanking out" because of severe anxiety about tests or public speaking). Insomnia and difficulty concentrating are also very common PTSD symptoms. These difficulties are compounded when the person is also depressed. ${ }^{61}$ Depression frequently leads not only to difficulty concentrating and a general slowing of mental processes, but also to a general listlessness and sense of despair which may prevent the person from presenting their case convincingly. All of these symptoms can seriously impair claimants' ability to present their case during proceedings before the IRB. ${ }^{62}$

\section{The IRB Training Manual on Victims of Torture}

The IRB Training Manual on Victims of Torture ${ }^{63}$ is, with some notable exceptions, a remarkably thorough, well-informed, and thoughtful document on dealing with asylum seekers and refugees who have been subjected to torture. As suggested in Guideline 8, much of the manual is also highly relevant when dealing with other vulnerable persons, particularly the many asylum seekers and refugees who have been exposed to other forms of organized violence such as rape, civil war, police brutality, death threats, domestic violence, and so on. The manual discusses issues such as the effect of posttraumatic stress on memory, concentration, and ability to tell one's story and the implications for credibility assessment. It also describes in considerable detail best practices for decision makers and RPOs when questioning vulnerable persons, advocating a technique based on the "Golden Rule," which is to "Let the claimants tell their stories in their own words and at their own pace." 64 The manual makes detailed suggestions for techniques to put the claimant at ease and build a relationship of respect and trust, as well as suggestions on how to approach sensitive topics such as torture or sexual abuse in a way that balances the need to probe the claim and test credibility, on the one hand, and to avoid re-traumatizing the claimant, on the other. Since Guideline 8 clearly encourages decision makers and RPOs to adopt the approach described in the Training Manual when dealing with vulnerable claimants, counsel could certainly draw upon it to support requests for a non-confrontational hearing in which the claimant is invited to describe the alleged incidents "in his or her own words and without interruption." 65

Although the information in the Training Manual on Victims of Torture is generally excellent, it contains a number of seriously misleading statements in its section "Malingering and PTSD." 66 These misconceptions appear to be largely based on a single article by Michael R. Harris and Philip J. Resnick, a continuing education text designed to teach mental health professionals techniques for the differential diagnosis of suspected malingerers in a clinical setting. ${ }^{67}$ The original article contains a number of oversimplifications, and the authors of the IRB Training Manual also appear to have misinterpreted some portions of the article. Here are some responses to the main misconceptions in the Training Manual's "Malingering and PTSD" section.

Misconception 1: Mental health professionals can be easily fooled by malingerers because diagnosis of PTSD and other mental disorders rests essentially on unverifiable self-reported symptoms. Mental disorders are easy to fake because defined 
by subjective criteria and lists of symptoms are easily available.

This is similar to saying that IRB decision makers are easily fooled because their decision rests almost entirely on the claimant's testimony, with little independent evidence to corroborate or contradict it. While it is true that deciding refugee claims presents a challenge, competent decision makers who know how to question a claimant and assess credibility, who are well-informed about country conditions, and who carefully examine all the evidence should generally be able to make well-founded decisions (although, like mental health professionals, they are not infallible!).

Although Harris and Resnick do write that PTSD is easy to fake because it is defined almost completely by subjective criteria and because lists of symptoms are easily available, they then go on to describe a series of techniques that allow detection of such malingering. These elementary techniques are familiar to any competent mental health professional. For example, Harris and Resnick write:

Inconsistency between the reported symptoms and clinical observations, the patient's reports and collateral history, symptom patterns with known psychiatric illnesses, or the patient's reported symptoms and their actual known functioning are all frequently seen in malingerers. Clinicians should be particularly careful to ask open-ended questions in suspected malingerers and let patients tell their complete story with few interruptions. Details can be clarified later with specific questions. ${ }^{68}$

Further, they also write:

The clinician should insist on detailed descriptions of symptoms. Malingering patients may know which symptoms to report but may be unable to give convincing descriptions or examples from their personal life. Behavioral observations during the examination may assist in evaluating symptoms of irritability, exaggerated startle response and difficulty concentrating. ${ }^{69}$

Again, one can draw a parallel with situation facing a Board member listening to an asylum seeker reciting a story "acquired" from a smuggler. At one level, one might say that it is easy for asylum seekers to draw on published accounts of successful claims to concoct a story calculated to fool Board members. On the other hand, a skilful Board member will, in most cases, quickly realize that the claimant's story is paper-thin and that she is unable to elaborate on the background circumstances surrounding the fabricated narrative. Likewise, it is indeed relatively easy for would-be malingerers to find descriptions of psychiatric symptoms and to recite them during an assessment, but this definitely does not mean that they can easily deceive a competent professional.
Mental health professionals conducting a clinical assessment do not rely solely on the patient's self-reported symptoms (e.g., nightmares, insomnia) but also base their assessment on direct observation of the patient's behaviour. According to DSM-IV criteria, ${ }^{70}$ for example, clinicians cannot pose a diagnosis of PTSD on the basis of self-reported symptoms alone; they must also observe certain specific behaviours such as exaggerated startle response, hypervigilance, irritability, or difficulty concentrating during the assessment interview. Such behaviours are very difficult to fake. More generally, mental health professionals undergo years of training during which accurate diagnosis of mental disorders is of central importance, as well as seeing dozens, if not hundreds, of patients suffering from such disorders over the years. They learn to reliably recognize the constellation of self-reported symptoms and behaviours that characterize different disorders. Part of their job is to detect malingering or exaggeration of symptoms, not only for the purpose of expert reports but also in order to decide whether medication or other treatment is warranted.

Misconception 2: Mental health professionals are reluctant to consider the possibility of malingering, even in obvious situations, for fear of damaging the therapeutic relationship based on unconditional acceptance.

Mental health professionals perform two main functions, assessment and treatment, involving two distinct attitudes and skill sets. During assessment, the professional's main concern is to accurately identify the precise nature of the person's mental health problems. A clinical assessment typically involves a series of detailed questions about the person's current difficulties; their emotional, cognitive, and physical symptoms; the circumstances in which the symptoms first appeared and how they evolved over time; relevant family and personal history; current psychosocial circumstances that may impact the person's mental state. While questioning the patient, the clinician will of course be attentive to the behaviours indicative of the person's cognitive and emotional state, such as body language, facial expressions, paralinguistic cues, emotional expression, nervousness, slow reactions, apathy, etc. The clinician will also closely monitor the patient's narrative for any sign of concentration problems, incoher ence, bizarre ideation, etc. In most cases, the clinician will have formed a working hypothesis quite early in the assessment process because the person's symptoms and behaviours fit a recognizable diagnostic pattern that the professional has learned to identify through years of training and experience. The rest of the interview will serve to test the hypothesis, to flesh out the diagnosis, and to better understand the needs of this particular patient. If clinicians note any apparent inconsistencies or exaggerations in the patient's account, they will probe further to determine whether this is a sign of ma- 
lingering or, on the contrary, an indication that the person's problems are more severe than initially thought or that the diagnosis should be revised.

Accuracy is of paramount importance during assessment. Although making moral judgments about patients is to be avoided, making well-informed cognitive judgments about the patient's condition is at the heart of mental health professionals' expertise and training. Detection of malingering is important for clinical as well as forensic reasons in order to avoid prescribing unnecessary medications or other treatment.

During treatment, the role of the mental health professional shifts to a focus on empathic listening and support. This is the stage at which many schools of psychotherapy advocate an attitude of unconditional acceptance, which means that the therapist should listen to the patient and try to understand her on her own terms in order to build the relationship of trust that is essential to psychotherapy. Throughout the treatment process, however, the professional will continue to monitor behavioural and narrative cues in order to further refine the diagnosis.

Harris and Resnick's assertion that psychiatrists are often reluctant to consider the possibility of malingering is based on studies conducted in clinical contexts such as emergency rooms rather than a forensic context. They quite rightly point out that in a clinical context, mental health professionals should be cautious before concluding that a patient is malingering because of the risk of overlooking symptoms of suicidal ideation, potential psychotic decompensation, or other serious problems. Even patients who exaggerate or fabricate symptoms may well have other, genuine mental health problems. Again, there are parallels in the field of refugee protection. For example, individuals who have genuinely suffered persecution sometimes make the mistake of basing their claim for asylum on a fabricated story because some unscrupulous smuggler has assured them that it's a winner. Others may lie about certain facts out of fear that they might be detrimental to their claim. Although lie detection is important, clinicians need to keep in mind that a person who malingering or exaggerating symptoms may be genuinely ill, just as IRB decision makers should remind themselves that a person who is lying or embellishing may nonetheless be a genuine refugee.

Misconception 3: "Psychiatrist's ability to detect lies in strangers is little better than chance" and their confidence in their ability to detect malingering is unrelated to their actual ability.

This statement is extraordinarily misleading. In support of this assertion, Harris and Resnick quote Paul Ekman's 1985 book Telling Lies. ${ }^{71}$ In fact, Ekman states that scientific studies show that "few people do better than chance in judging whether someone is lying or truthful,"72 and that this applies not only to the general population but also to profes- sionals whose job involves detection of deception, be they psychiatrists, police officers, polygraph examiners, or others. Furthermore, the person's confidence in their ability to detect lies is unrelated to their actual ability. In the twenty years since Ekman wrote these words, multiple scientific studies of deception detection have confirmed his findings, consistently showing that not only psychiatrists and clinical psychologists, but also judges, police officers, customs officials, parole officers, polygraph examiners, and auditors are on average no better than non-professionals in detecting deception, which means little better than chance. ${ }^{73}$ A recent paper reviewing the results of over two hundred scientific studies involving a total of more than 24,000 participants confirmed that professionals whose job involves detection of deception were in general no more accurate at lie detection than the general population, and that average accuracy is about 54 per cent (just 4 per cent better than chance). ${ }^{74}$ The only professional groups who appeared to be somewhat more accurate at detecting deception were US Secret Service and CIA agents, although this finding may well be spurious because of small group size. ${ }^{75}$ Psychiatrists and clinical psychologists were at least as good as US federal and state judges at distinguishing truth from lies, although both judges and mental health professionals were only very slightly better than the general population. ${ }^{76}$ The same studies show that there is little or no relation between confidence in one's ability to detect deception and actual ability. On the other hand, some individuals are consistently above average in their ability to detect deception, but this appears to be linked to their cognitive style rather than to their profession, gender, age, or other demographic characteristics. ${ }^{77}$ Several studies indicate that observing a person over a longer period of time and, better yet, in different contexts tends to increase accuracy. ${ }^{78}$

Studies of deception detection generally involve viewing a brief videotaped excerpt of a person either lying or telling the truth about a particular event. This is similar to the task facing a mental health professional or an IRB decision maker who is trying to decide whether a refugee claimant is telling the truth about the traumatic events experienced in the country of origin. However, it may well be somewhat different from the main task performed by mental health professionals during assessments, which is to determine whether a constellation of symptoms and behaviours are consistent with a typical diagnostic picture. In the latter case, the clinician is comparing the symptoms displayed and recounted by the patient to a diagnostic template. It would seem plausible that it would be easier for a clinician to accurately identify symptoms that are inconsistent with a diagnostic template about which she is an expert than to judge the veracity of a narrative about a unique incident, which cannot be compared to a template and about which the listener has no 
specialized knowledge. In other words, I would predict that mental health professionals' ability to detect malingering would generally be considerably better than chance because this involves identifying deviations from a characteristic pattern of symptoms that the professional has seen many times before. Be that as it may, the one thing that has been conclusively demonstrated by multiple scientific studies is that mental health professionals are at least as good as judges, customs officials, police officers, or the general population at distinguishing truth from lies.

Misconception 4: Mental health professionals "may" rely solely on symptom checklists or leading questions or self-reporting, not spend enough time with the patient, be swayed by vivid stories, not be sufficiently knowledgeable, or be otherwise incompetent or unprofessional

The Training Manual states that there are "a number of reasons why a claimant might be able to fool the ordinary professional," notably because professionals "may" engage in a host of poor practices such as relying solely on leading questions or symptom checklists, not spending enough time with the patient, being swayed by vivid stories, not being sufficiently knowledgeable, and so on. ${ }^{79}$ This highly prejudicial assertion is purely hypothetical: a claimant "might" be able to fool a professional, who "may" be incompetent. There is absolutely no evidence as to the frequency of such practices. Obviously, in any profession, be it mental health, law, or any other, one can find individuals who are unethical or do shoddy work. This says nothing about the integrity or competence of the profession as a whole.

Some of the examples of supposed shoddy practices by mental health professionals are visibly based on misinterpretation of the quoted source. For example, the manual states, "In one study the use of leading questions or symptom checklists allowed malingerers unfamiliar with psychiatric disorders to qualify for diagnoses of major depression and posttraumatic stress disorder." 80 In fact, this was a study in which college students were provided with a list of symptoms drawn from the DSM-IV description of four disorders, including PTSD and depression, and asked to check off the symptoms that they thought were experienced by people suffering from these disorders. ${ }^{81}$ Not surprisingly, faced with a list of symptoms, a large proportion of the college students were able to guess which ones to endorse. This is very different from convincing a mental health professional that one is actually experiencing such symptoms during a face-to-face assessment interview or therapy session.

In the real world, mental health professionals do not pose a diagnosis of PTSD or depression or any other diagnosis based only on the patient's answers to a symptom checklist. To do so would be contrary to elementary professional ethics. In addition, many diagnoses cannot be made solely on the basis of self-reported symptoms. Before posing a diagnosis of PTSD, for example, the clinician must also observe certain behaviours and be convinced that the person's ability to function in daily life is at least somewhat impaired. If used at all in the context of a clinical assessment, questionnaires are filled out after the interview as an additional means to check the diagnosis. Symptom checklists are primarily used for research, particularly in the context of anonymous studies in which respondents have no incentive to invent or exaggerate symptoms.

Other assertions, such as "The professional may not spend enough time with the claimant" or "may not being [sic] sufficiently knowledgeable about PTSD and/torture [sic]" 82 are not sourced and appear to be purely gratuitous. The manual certainly provides no evidence to support them.

The reason that I have discussed at such length the Training Manual's misleading statements about mental health professionals is that such negative stereotypes of mental health professionals appear to be quite pervasive within the IRB. This impression is based on interviews with former Board members and on analysis of a large number of recent Refugee Protection Division decisions (2004-2008) involving psychiatric or psychological evidence. It is certainly disturbing to read such caricatural negative stereotypes in the Training Manual on Victims of Torture, which is otherwise a very thoughtful and well-researched document. Even more disturbing, this type of negative stereotyping too often leads Board members to discount expert reports written by competent mental health professionals and based on thorough clinical assessments.

\section{Conclusion}

The adoption of the Guideline on Procedures with Respect to Vulnerable Persons Appearing Before the IRB is clearly an important step in the right direction. Thus, it explicitly recognizes the principle that vulnerable persons appearing before the Board have the right to procedural accommodations to ensure that they receive a fair hearing. The Guideline defines sources of vulnerability in broad and inclusive terms and confirms that Board members have considerable discretion to devise procedural accommodations tailored to fit the vulnerable person's particular needs. Decision makers are strongly encouraged to adopt the approach proposed in the Training Manual on Victims of Torture when questioning vulnerable persons in order to minimize re-traumatization. So far, the Board has accepted most applications made under Guideline 8, indicating that there is a genuine desire to take the needs of vulnerable persons into account.

For the moment Guideline 8 serves only to provide procedural accommodations. However, one can reasonably argue that in order to achieve the Guideline's stated purpose of ensuring that vulnerable persons are not disadvantaged in 
presenting their case, Board members should also take such persons' psychological difficulties into account when assessing their credibility. Such an interpretation would go a long way toward making the refugee protection processes fairer.

However, there are a number of problems with the Guideline. First, limiting application of the Guideline to cases involving exceptionally severe impairment is unduly restrictive. Procedural accommodations should be permitted whenever there is reason to believe that they might make it easier for the person to tell her story or decrease her level of distress. Second, Board members do not have the expertise to review a mental health professional's opinion as to the applicant's mental health status. For the purpose of procedural accommodations, a report by a qualified mental health professional concluding that the person has mental health problems likely to impair her ability to present her case should be treated as conclusive proof of vulnerability.

Ultimately, though, the main problem with Guideline 8 is the fact that it is purely procedural and does not address the many other problems faced by vulnerable asylum seekers and permanent residents, briefly outlined in the introduction to this paper. There is an urgent need for immigration authorities, refugee rights advocates, and mental health professionals to make a concerted effort to develop policies designed to better meet the needs of vulnerable persons. It is to be hoped that the Guideline on Procedures with Respect to Vulnerable Persons Appearing Before the IRB will prove to be the first step on a long road toward greater fairness for vulnerable persons seeking protection in Canada.

\section{Notes}

1. Guideline 8 - Guideline on Procedures with Respect to Vulnerable Persons Appearing Before the Immigration and Refugee Board of Canada, online: Immigration and Refugee Board, <http://www.irb-cisr.gc.ca/en/references/ policy/guidelines/vulnerable_e.htm\#note1> [Guideline on Vulnerable Persons].

2. Immigration and Refugee Protection Act, R.S.C. 2001, c. 27, s. 58(3).

3. UK Home Office guidelines state that detainees should be given a physical and psychological examination within twenty-four hours of admission and that torture survivors should never be detained other than in exceptional cases. In December 2008, the UK government was condemned to pay $£ 38,000$ in damages to a female torture survivor from Cameroon who had been unlawfully detained after seeking asylum in the UK. Torture survivor's six-month detention in UK signals urgent need for asylum reform, Medical Foundation for the Care of Victims of Torture, online: <http:// www.torturecare.org.uk/news/latest_news/2294> (date accessed: 8 January 2009).
4. C.Y.R (Re), [2008] RPDD 10 (QL).

5. TWQ (Re) [2007] RPDD No. 26 (QL), X (Re), 2007 CanLII 49705 (IRB).

6. Training Manual on Victims of Torture, online: Immigration and Refugee Board, <http://www.irb-cisr.gc.ca/en/ about/tribunals/rpd/victorture/index_e.htm)> [Training Manual].

7. Guideline on Vulnerable Persons, supra note 1, ss. 1.4, 2.1, 3.1.

8. Ibid., s. 1.5 .

9. Ibid., s. 5.1.

10. Ibid., s. 3.3.

11. Ibid., ss. 1.5, 2.1 .

12. Ibid., s. 1.2, 2.2.

13. Ibid., s. 2.3 .

14. Ibid., s. 1.5 , note 3 .

15. Ibid., s. 7.1.

16. Ibid., s. 7.5.

17. Immigration and Refugee Protection Act, supra note 2, c. 27, s. 167(2); and Guideline on Vulnerable Persons, supra note 1, s. 12.1 .

18. Sharma c. Canada (Ministre de la Citoyenneté et de l'Immigration), [2008] CF 908 [Sharma].

19. C.H.F.(Re), [2007] RPDD 9 (QL), X (Re), [2007] CanLII 47772 (IRB); Sharma, supra note 18.

20. Guideline on Vulnerable Persons, supra note 1, s. 4.1.

21. Ibid., s. 4.2h).

22. Ibid., s. 9.

23. Ibid., s. 10.1 .

24. Ibid., s. 10.1, note 10 .

25. Ibid., ss. 2.4, 7.3.

26. Ibid., ss. 7.3, 8.6.

27. Information provided by Marie Chevrier and Patricia Auron of the IRB.

28. Ibid., s. 2.4, 7.3, 8.6.

29. Ibid., s. 5.1 .

30. Ibid., ss. 5.2, 5.3 .

31. Ibid., s. 5.2.

32. Ibid., s. 8.5 .

33. Ibid., s. 5.2.

34. Information provided by Marie Chevrier and Patricia Auron of the IRB.

35. A search of the Federal Court, RefLex, Canada Legal Information Institute (IRB), and Quicklaw (IRB) databases was last carried out on January 8, 2009, using the following keywords: (refugee and vulnerable and guideline) OR "Guideline on Procedures with Respect to Vulnerable"

36. In Canada (Citizenship and Immigration) v. Jama, [2007] CanLII 12831 (IRB), the Immigration Division refused to compel the Minister to issue a Danger Opinion concerning a detained refugee, noting that Guideline 8 does not apply to the Minister's officers; in Evdokimov v. Canada (Public Safety and Emergency Preparedness), [2007] CanLII 47283 (IRB), the Immigration Appeal Division rescinded a removal order against a permanent resident with schizophre- 
nia and substance abuse who had committed numerous criminal offenses, alluding briefly to the Guideline; in XZA (Re) [2007] RPDD 19 (QL), X (Re) [2007] CanLII 48212 (IRB), the Board accepted to reopen the case of a fourteenyear-old girl who, after her initial hearing, disclosed to her therapist that she had undergone severe sexual and physical abuse by relatives in her country of origin; in TWQ, supra note 5, an Ethiopian woman with bipolar disorder was allowed to submit a substantially amended Personal Information Form (PIF) after admitting that her original narrative was untruthful, and was later accepted as a refugee based on the risk of severe stigmatization; in CHF (Re), [2007] RPDD 9 (QL), X (Re), [2007] CanLII 47772 (IRB), a Rwandan genocide survivor with PTSD was identified as vulnerable based on a psychologist's report indicating that he was very reluctant to talk about his experiences and tended to become confused about some of the details of his story; in HKL (Re), [2007] RPDD 9 (QL), X (Re), [2007] CanLII 47401 (IRB), a young intellectually handicapped Albanian woman who claimed to have been raped by her boyfriend was considered vulnerable; in SXV (Re), [2007] RPDD 41, $X(R e)$ [2007] CanLII 60075 (IRB), a sixteen-year-old girl who had suffered severe sexual abuse was considered vulnerable; in $X(R e)$, August 1, 2007, RPD file TA6-14695, a woman with chronic PTSD and intermittent memory problems due to a subarachnoid hemorrhage following a cerebral aneurysm was identified as vulnerable.

37. IYT (Re), [2007] RPDD 14 (QL), X (Re), 2007 CanLII 47287 (IRB).

38. Ibid. at para. 10.

39. Guideline on Vulnerable Persons, supra note 1,s. 2.3.

40. Ibid., s. 2.1 .

41. IYT, supra note 39 at para. 4.

42. Orozco v. Canada (Citizenship and Immigration) 2008 FC 270, affirming BIP (Re)[2007] RPDD 20 (QL), X (Re), [2007] CanLII 47726 (IRB)

43. Ibid. at para. 30 .

44. Sharma c. Canada (Citoyenneté et Immigration) $2008 \mathrm{CF}$ 908, affirming Kirpal Sharma and Santi Sharma, December 13, 2007, RPD files MA6-04257 \& MA6-04258.

45. See e.g. Afonso v. Canada (Minister of Citizenship and Immigration) [2007] FC 51; Villarreal Zempoalte v. Canada (Citizenship and Immigration) [2007] FC 263; Assouad v. Canada (Minister of Citizenship and Immigration) [2006] FC 955; Henry v. Canada (Minister of Citizenship and Immigration) [2006] FC 1060; Myle v. Canada (Minister of Citizenship and Immigration) [2006] FC 871; Sivarajathurai v. Canada (Minister of Citizenship and Immigration) [2006] FC 905; Tesema v. Canada (Minister of Citizenship and Immigration) [2006] FC 1417; Martinez Martinez v. Canada (Minister of Citizenship and Immigration) [2006] FC 403; Ruiz v. Canada (Minister of Citizenship and Immigration) [2005] FC 1339.

46. See Ameir v. Canada (Minister of Citizenship and Immigration) [2005] FC 876.
47. Guideline on Vulnerable Persons, supra note 1, s. 10.1.

48. Ronald C. Kessler et al., "Posttraumatic Stress Disorder in the National Comorbidity Survey" (1995) 52 Archives of General Psychiatry 1048; Ronald C. Kessler, "Posttraumatic Stress Disorder: The Burden to the Individual and to Society" (2000) 62:suppl. 5 Journal of Clinical Psychiatry 4; Naomi Breslau et al., "Trauma and Posttraumatic Stress Disorder in the Community" (1998) 55 Archives of General Psychiatry 626; Naomi Breslau, "Epidemiology of Trauma and Posttraumatic Stress Disorder" in Rachel Yehuda, ed., Psychological Trauma (Washington, DC: American Psychiatric Association Press, 1998), at 1-29; Mark Creamer, Philip Burgess, \& Alexander C. McFarlane, "Post-traumatic Stress Disorder: Findings From the Australian National Survey of Mental Health and Well-being" (2001) 31 Psychological Medicine 1237; Fran H. Norris et al., "Epidemiology of Trauma and Posttraumatic Stress Disorder in Mexico" (2003) 112 Journal of Abnormal Psychology.

49. Grant N. Marshall et al., "Mental Health of Cambodian Refugees 2 Decades After Resettlement in the United States" (2005) 294 Journal of the American Medical Association 571; Richard F. Mollica et al., "Dose-effect Relationships of Trauma to Symptoms of Depression and Post-traumatic Stress Disorder Among Cambodian Survivors of Mass Violence" (1998) 173 British Journal of Psychiatry 48; Norris et al., supra note 48; Zachary Steel et al., "Long-term Effect of Psychological Trauma on the Mental Health of Vietnamese Refugees Resettled in Australia: A Population-based Study" (2002) 360 The Lancet.

50. Norris et al., supra note 48.

51. Joop T. V. M. de Jong et al., "Lifetime Events and Posttraumatic Stress Disorder in 4 Postconflict Settings" (2001) 286 Journal of the American Medical Association 555.

52. Ibid.

53. Kessler et al., supra note 48; Kessler, supra note 48.

54. Breslau, supra note 48; Creamer, Burgess, \& McFarlane, supra note 48; Kessler et al., supra note 48; Marshall et al., supra note 49; Richard F. Mollica et al., "Longitudinal Study of Psychiatric Symptoms, Disability, Mortality, and Emigration Among Bosnian Refugees" (2001) 286 Journal of the American Medical Association 546; Shakeh Momartin et al., "Comorbidity of PTSD and Depression: Associations With Trauma Exposure, Symptom Severity and Functional Impairment in Bosnian Refugees Resettled in Australia" (2004) 80 Journal of Affective Disorders 231; Arieh Y. Shalev et al., "Prospective Study of Posttraumatic Stress Disorder and Depression Following Trauma" (1998) 155 American Journal of Psychiatry 630.

55. Creamer, Burgess, \& McFarlane, supra note 48.

56. Marshall et al., supra note 49; Shakeh Momartin et al., "Dimensions of Trauma Associated With Posttraumatic Stress Disorder (PTSD) Caseness, Severity and Functional Impairment: A Study of Bosnian Refugees Resettled in Australia" (2003) 57 Social Science \& Medicine 775; Momartin et al., supra note 54; Derrick Silove et al., "Anxiety, Depres- 
sion and PTSD in Asylum seekers: Association with Premigration trauma and post-migration stressors" (1997) 170 British Journal of Psychiatry 351.

57. Richard F. Mollica et al., "Disability Associated With Psychiatric Comorbidity and Health Status in Bosnian Refugees Living in Croatia," Journal of the American Medical Association 281 (1999): 433-439; Momartin et al., "Comorbidity of PTSD and Depression," supra note 54; Momartin et al., "Dimensions of Trauma," supra note 56; Shalev et al., supra note 54.

58. Anke Ehlers, Ann Hackmann, \& Tanja Michael, "Intrusive Re-experiencing in Post-traumatic Stress Disorder: Phenomenology, Theory, and Therapy" (2004) 12 Memory 403.

59. Sven-Ake Christianson, "Emotional Stress and Eyewitness Memory: A Critical Review” (1992) 112 Psychological Bulletin 284; Jane Herlihy, Peter Scragg, \& Stuart Turner, “Discrepancies in Autobiographical Memories-Implications for the Assessment of Asylum Seekers: Repeated Interviews Study" (2002) 324 British Medical Journal 324.

60. Ehlers, Hackmann, \& Michael, supra note 58; Robert J. Ursani, Carol S.Fullerton, \& David M. Benedek, "Peritraumatic dissociation: Time perception and cerebellar regulation of psychological, interpersonal, and biological processes," in Eric Vermetten, Martin Dorahy, \& David Spiegel, eds., Traumatic Dissociation: Neurobiology and Treatment (Washington, DC: American Psychiatric Publishing, 2007).

61. Momartin et al., "Comorbidity of PTSD and Depression," supra note 54 .

62. Herlihy, Scragg, \& Turner, supra note 59; Cécile Rousseau et al., "The complexity of determining refugeehood: A multidisciplinary analysis of the decision-making process of the Canadian Immigration and Refugee Board" (2002) 15:1 Journal of Refugee Studies 43; Zachary Steel, Naomi Frommer, \& Derrick Silove, "Part I-The mental health impacts of migration: the law and its effects. Failing to understand: refugee determination and the traumatized applicant" (2004) 27 Int'l. J.L. \& Psychiatry 511.

63. Training Manual, supra note 6.

64. Ibid. at 26.

65. Ibid. at 36 .

66. Ibid. at 43-47.

67. Michael R. Harris and Philip J. Resnick, "Suspected Malingering: Guidelines for Clinicians” (2003) 20 Psychiatric Times 68.

68. Ibid. at 69.

69. Ibid. at 72 .

70. Diagnostic and Statistical Manual of Mental Disorders, 4th ed. (Washington, D.C.: American Psychiatric Association, 1994) [DSM-IV].
71. Paul Ekman, Telling Lies: Clues to Deceit in the Marketplace, Politics, and Marriage (New York: Norton, 1985).

72. Ibid. at 162 .

73. Charles F. Bond, Jr., \& Bella M. DePaulo, "Accuracy of Deception Judgments" (2006) 10:3 Personality and Social Psychology Review 214; Paul Ekman \& Maureen O’Sullivan, "Who Can Catch a Liar?" (1991) 46:9 American Psychologist 913; Paul Ekman, Maureen O’Sullivan, \& Mark G. Frank, "A Few Can Catch a Liar" (1999) 10:3 Psychological Science 263; Eugenio Garrido, Jaume Masip, \& Carmen Herrero, “Police Officers' Credibility Judgments: Accuracy and Estimated Ability" (2004) 39:4 International Journal of Psychology 254; Stephen Porter, Mike Woodworth, \& Angela R. Birt, "Truth, Lies, and Videotape: An Investigation of the Ability of Federal Parole Officers to Detect Deception" (2000) 24:6 Law and Human Behavior 643; Aldert Vrij, Detecting Lies and Deceit: The Psychology of Lying and the Implications for Professional Practice (Chichester: Wiley, 2000); Aldert Vrij \& Samantha Mann, "Who killed my relative? Police Officers' ability to detect real-life high-stake lies" (2001) 7:2 Psychology, Crime \& Law 119.

74. Bond \& DePaulo, supra note 73.

75. Ibid.; Ekman, O'Sullivan, \& Frank, supra note 73.

76. Ekman \& O'Sullivan, supra note 73; Ekman, O'Sullivan, \& Frank, supra note 73.

77. Ekman \& O’Sullivan, supra note 73; Garrido, Masip, \& Herrero, supra note 73; Porter, Woodworth, \& Birt, supra note 73; Vrij, supra note 73.

78. Garrido, Masip, \& Herrero, supra note 73; Porter, Woodworth, \& Birt, supra note 73; Vrij, supra note 73.

79. Training Manual, note 65 at 44 .

80. Ibid. at 44 , note 52 .

81. Paul R. Lees-Haley and John T. Dunn, "The Ability of Naive Subjects to Report Symptoms of Mild Brain Injury, PostTraumatic Stress Disorder, Major Depression, and Generalized Anxiety Disorder" (1994) 50:2 Journal of Clinical Psychology 252.

82. Training Manual, note 65 at 45.

Janet Cleveland, Ph.D., is a researcher on refugee protection issues affiliated with the Research Institute of the McGill University Health Centre and the McGill University Oppenheimer Chair in International Public Law. She is also a clinical psychologist and former lawyer. Funding for the study on which this article is based was provided by a grant from the Canadian Institutes of Health Research to a research team composed of Cécile Rousseau (Principal Investigator), Janet Cleveland, François Crépeau, and Laurence Kirmayer.

(C) Janet Cleveland, 2008. This open-access work is licensed under a Creative Commons Attribution-NonCommercial 4.0 International License, which permits use, reproduction and distribution in any medium for non-commercial purposes, provided the original author(s) are credited and the original publication in Refuge: Canada's Journal on Refugees is cited. 